\title{
Disrupting the future
}

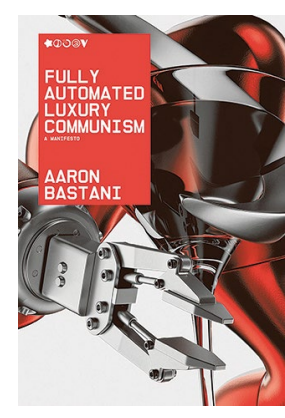

\author{
Fully Automated \\ Luxury Communism: \\ A Manifesto
}

By Aaron Bastani

VERSO: 2019. 288PP. $\notin 16.99$

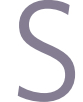
everal years ago, a new slogan appeared: fully automated luxury communism (FALC, for short). The rallying cry of a revitalized young left with big ideas, it was defiantly utopian, uncompromisingly ambitious, and a bit tongue-in-cheek. Aaron Bastani's new book Fully Automated Luxury Communism, however, takes its proposition very seriously. We are on the verge, he argues, of genuine abundance, real freedom, and the end of work - for all.

At a time when dystopia seems more likely, this is a striking claim. Bastani affirms that capitalism is currently beset by crises: climate change, resource scarcity, social ageing and widespread unemployment, which will only increase as automation advances. But these crises are also a sign that something else is on the horizon. This is where FALC comes in.

We are living through what Bastani calls, in language echoing Silicon Valley, the Third Disruption: a shift in human life as monumental as the shift to settled agriculture twelve-thousand years ago (the First Disruption) and the Industrial Revolution (the Second). The Third Disruption is epitomized by advances in information technology that promise some might say threaten - to replace human labour with computing power. For Bastani, however, "peak human" is a good thing (p. 74). At last, a world without scarcity or work truly is possible - but only if politics directs the Third Disruption for the benefit of all.

The core principle of this new rupture is that information, as Stewart Brand once said, wants to be free. Information is the kind of good wherein each marginal unit can be produced without additional cost. Nearly all the cost of producing an album, for example, goes into the first recording further copies cost almost nothing. The costs of storing information are plummeting, which means that informational goods are nearly unlimited. But this is a problem for capitalism: scarcity makes goods valuable. If anyone can make a copy for free, why would they buy one? Thus, to realize a profit, capitalism must create artificial scarcity in the form of intellectual property rights.

Nature, by contrast, is not scarce but bountiful: "Nature provides us with virtually free, limitless energy," Bastani writes (p. 102). Capturing it will make nearly anything possible - including the extraction of mineral resources from asteroids, which in turn will "permi $[t]$ humanity to entirely exceed our present limits" (p. 38). Already, solar power is becoming drastically cheaper, outcompeting fossil fuels and bringing electricity to the global south. Biotechnology advances will make it possible to edit out genetic malfunctions so that we live longer, healthier lives than ever before and allow us to grow steaks in labs, sparing both cows and climate. Information technology will even make it possible to mass-produce the likes of Dom Pérignon.

Yet, for the true possibilities of these technologies to be realized, a populist politics - what Bastani describes as "luxury populism" - will have to claim them for all (p. 188). Against both neoliberals who impose austerity and greens who insist on sacrifice, luxury populism promises that everyone can live like a billionaire.

Throughout, Bastani confidently declares that technological wonders will soon be the norm. Some of his claims strain credibility, such as when he cites an entrepreneur's prediction that lab-grown bluefin tuna will be price-competitive by $2020-$ a prospect that, halfway through 2019 , seems unlikely. Breathless declarations that we are entering a new age, moreover, have been made repeatedly over the past four decades. Remember when the internet was going to set us all free? It is true, of course, that capitalism is changing. It is less clear, however, whether Bastani's conclusions are warranted. He asserts that "capitalism, at least as we know it, is about to end" (p. 23) - but the "as we know it" is crucial. Capitalism has survived a great many crises by simply shape-shifting.

Though communism, on the other hand, has been attempted before, Bastani argues that it was simply not possible until now because there were no technologies capable of abolishing scarcity and work. It is a bit convenient that now is the only time that communism has ever been possible. (For that matter, why stop at the Third Disruption? Why not the Fourth, or Fifth, or Tenth?) But this conclusion is baked into Bastani's definition of abundance. Freedom is possible only when there is no scarcity whatsoever: thus human liberation requires asteroid mining. Luxury, meanwhile, means living like a billionaire, or like "a music video" (p. 192). But this misunderstands what luxury is: a necessarily scarce good that derives its status from relative social position rather than sheer material quantity. Paradoxically, in a world where computing power is plentiful, it is human labour that is becoming a luxury - poor children are taught by iPad, while rich ones receive lavish human attention. (Bastani has little to say about the kinds of human labour, like education and care work, that resist automation.) Similarly, if 3D-printed steaks are cheap, meat from cows will be even more prized. Abundance, that is, is a subjective, relational condition rather than an objective one.

Although Bastani is unequivocal about the threat posed by climate change, he says remarkably little about other ecological crises, from water shortages to declining biodiversity. Such problems are essentially chalked up to land use: once we grow meat in vats, we can re-wild the earth. Yet a great deal hangs on the premise that the combination of asteroid mining, solar energy and free information will overcome all physical limits. If any element fails to live up to expectations, FALC collapses. Why put every lab-grown egg in such a basket - one that venture capitalists are currently holding? Meat replacements and solar panels are surely part of any sustainable future, but they cannot be the whole of it.

Bastani is surely right that contemporary technology can help improve most people's lives, while also easing human pressures on Earth, and that bold political action will be necessary in order to pry its potential from the grip of a wealthy few. His insistence that the future need not be grim is welcome amidst the current chorus of doomsaying. But we should hope that he is wrong about the futility of the $\mathrm{C}$ short of the FAL.

Reviewed by Alyssa Battistoni

Department of Political Science, Yale University,

New Haven, CT, USA.

e-mail:alyssa.battistoni@yale.edu

Published online: 9 August 2019 https://doi.org/10.1038/s41893-019-0360-9 